\title{
Acute Caffeine Intake Enhances Mean Power Output and Bar Velocity during the Bench Press Throw in Athletes Habituated to Caffeine
}

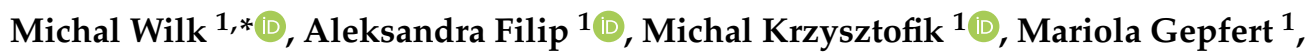 \\ Adam Zajac ${ }^{1}$ (D) and Juan Del Coso ${ }^{2} \mathbb{D}$ \\ 1 Institute of Sport Sciences, The Jerzy Kukuczka Academy of Physical Education, 40-065 Katowice, Poland; \\ a.filip@awf.katowice.pl (A.F.); m.krzysztofik@awf.katowice.pl (M.K.); m.gepfert@awf.katowice.pl (M.G.); \\ a.zajac@awf.katowice.pl (A.Z.) \\ 2 Centre for Sport Studies, Rey Juan Carlos University, 28942 Fuenlabrada, Spain; juan.delcoso@urjc.es \\ * Correspondence: m.wilk@awf.katowice.pl
}

Received: 3 January 2020; Accepted: 3 February 2020; Published: 4 February 2020

\begin{abstract}
Background: The main objective of the current investigation was to evaluate the effects of caffeine on power output and bar velocity during an explosive bench press throw in athletes habituated to caffeine. Methods: Twelve resistance trained individuals habituated to caffeine ingestion participated in a randomized double-blind experimental design. Each participant performed three identical experimental sessions $60 \mathrm{~min}$ after the intake of a placebo, 3, and $6 \mathrm{mg} / \mathrm{kg} / \mathrm{b} . \mathrm{m}$. of caffeine. In each experimental session, the participants performed 5 sets of 2 repetitions of the bench press throw (with a load equivalent to $30 \%$ repetition maximum (RM), measured in a familiarization trial) on a Smith machine, while bar velocity and power output were registered with a rotatory encoder. Results: In comparison to the placebo, the intake of caffeine increased mean bar velocity during 5 sets of the bench press throw $(1.37 \pm 0.05$ vs. $1.41 \pm 0.05$ and $1.41 \pm 0.06 \mathrm{~m} / \mathrm{s}$ for placebo, 3 , and $6 \mathrm{mg} / \mathrm{kg} / \mathrm{b} . \mathrm{m}$., respectively; $p<0.01$ ), as well as mean power output ( $545 \pm 117 \mathrm{vs.} 562 \pm 118$ and $560 \pm 107 \mathrm{~W} ; p<0.01)$. However, caffeine was not effective at increasing peak velocity $(p=0.09)$ nor peak power output $(p=0.07)$ during the explosive exercise. Conclusion: The acute doses of caffeine before resistance exercise may increase mean power output and mean bar velocity during the bench press throw training session in a group of habitual caffeine users. Thus, caffeine prior to ballistic exercises enhances performance during a power-specific resistance training session.
\end{abstract}

Keywords: ballistic exercise; upper limbs; resistance exercise; ergogenic substances; sport performance

\section{Introduction}

Caffeine (CAF) is one of the most common substances used in sport which enhances physical performance [1]. Although CAF may affect various body tissues [2,3], there is a growing body of evidence in animal [4] and human models [5] sustaining the ability of CAF to act as an adenosine antagonist, as the main mechanism behind CAF ergogenic effect. Current research recommends doses of CAF ranging from 3 to $6 \mathrm{mg} / \mathrm{kg}$ body mass to elicit ergogenic benefits, while the time of ingestion (from 30 to $90 \mathrm{~min}$ before exercise) and the form of ingestion (pills, liquid, chewing gum) are less significant as CAF is rapidly absorbed after ingestion [6]. However, the optimal protocol of CAF supplementation may differ based on the type and duration of exercise, previous habituation to CAF and the type of muscle contraction [6-10].

Acute CAF intake causes a slightly different response to upper and lower body exercise [10], despite the lack of a mechanisms explaining this phenomenon. A recent meta-analysis about the effects of CAF on muscle strength and power output found that CAF significantly improved upper but not lower body 
strength [7]. Although the outcomes of the first investigations were contradictory [11-13], more recent studies have found a clear effect of CAF on several forms of upper body muscle performance [14-16], when the used dose was at least $3 \mathrm{mg} / \mathrm{kg} / \mathrm{b} . \mathrm{m}$. [17]. Interestingly, the effect of CAF on upper body muscle performance may be partially dampened in athletes habituated to CAF because the regular use of CAF-containing products [18] may develop tolerance to this substance. It must be noticed that this decreased ergogenic effect of CAF is not removed even with the ingestion of doses $>9 \mathrm{mg} / \mathrm{kg} / \mathrm{b} . \mathrm{m}$. [19,20].

Most studies on the acute effects of CAF on upper body muscle performance used the bench press exercise. The bench press exercise is widely used as a means of developing strength and power of the upper limbs [21,22]. However, other authors, recommend the use of ballistic exercises for the development of upper body power, such as the bench press throw (BPT) [23,24]. Specifically, to increase power output, the loads ranging from $0 \%$ to $50 \%$ of one-repetition maximum (1 RM) moved at maximal speed are recommended as the most potent loading stimuli for improving power output [23]. However, this type of routine can only be performed on a Smith machine while using the BPT exercise (i.e., maximal bar velocity is obtained at the moment of throw). The traditional free-weight bench press exercise does not allow for the attainment of maximal velocity of execution (i.e., velocity equals $0 \mathrm{~m} / \mathrm{s}$ at maximal arm extension). Thus, ballistic exercises could be an optimal choice for power training as they allow for greater velocity, and muscle activation in comparison to similar traditional resistance training routines [21]. Perhaps, the main asset of the BPT is the maximum acceleration of a given load, which ultimately produces high movement velocity in a short time [25]. In this respect, the loads applied in ballistic exercises during training will depend on the specific requirements of particular sport disciplines and will determine success in numerous power-based competitions [23]. Furthermore, the BPT performance has been associated with overall performance in different sport-specific tasks [26-29]. Therefore, it seems reasonable to use the BPT as a means of testing upper-body ballistic performance. Although the BPT is indicated as the most effective exercise for developing power of the upper limbs [30], previous studies have not determined the acute effects of CAF on power output and bar velocity during this type of exercise.

Burke [31] has suggested that, in the current literature, there is a lack of data about the practical use of supplements in competitive sports because experimental protocols are often different from sports practice. In case of CAF, most studies considering the acute effects of this supplement were assessed on the basis of only a single set of an exercise [7,8,32], while real resistance training sessions in trained individuals rarely contain only one set of a particular exercise [31]. On the other hand, the investigations analyzing the acute effects of CAF on performance during successive sets of resistance exercises are scarce. Bowtell et al. [3] showed that pre-exercise CAF $(6 \mathrm{mg} / \mathrm{kg} / \mathrm{b} . \mathrm{m}$.) intake improved total exercise time during 5 sets of one-legged knee extensions performed to failure in comparison to a placebo (PLAC). It is worth noting that this ergogenic effect was achieved despite significantly lower muscle phosphocreatine concentration $(\mathrm{PCr})$ and $\mathrm{pH}$ in the latter sets of an exercise in the $\mathrm{CAF}$ trial. Further, CAF ingestion $(6 \mathrm{mg} / \mathrm{kg} / \mathrm{b} . \mathrm{m}$.) attenuated the increase in interstitial potassium during one-legged knee extensions at $20 \mathrm{~W}(10 \mathrm{~min})$ and $50 \mathrm{~W}(3 \times 3 \mathrm{~min})$ measured using microdialysis [33], which resulted in a $16 \%$ improvement in high-intensity exercise capacity.

Most studies related to the acute impact of CAF intake on power output and bar velocity have used participants unhabituated to CAF or individuals with low-to-moderate daily consumption of this stimulant $[11,16,34]$. However, the analysis of urinary CAF concentrations after official competitions suggests that CAF is widely employed before or during exercise to enhance performance $[35,36]$. This would mean that it is highly likely that some athletes are habituated to CAF due to daily consumption of caffeine-containing products. The existence of athletes habituated to CAF may be particularly common in sports such as cycling, rowing, triathlon, athletics, and weightlifting, sport disciplines that benefit from the use of ballistic exercises during training to increase power output. Habitual CAF intake modifies physiological responses to acute ingestion of this stimulant by the up-regulation of adenosine receptors $[37,38]$. This effect would produce a progressive reduction of CAF ergogenicity in those athletes consuming CAF on a regular basis, because the newly created adenosine receptors may 
bind to adenosine and induce fatigue. However, the fact of habituation to the ergogenic benefits of CAF is still inconclusive. The studies by Dodd et al. [39] and de Souza [40] showed similar responses to endurance exercise after acute CAF intake between low and habitual CAF consumers, although this is not always the case [41]. Considering the above, the use of cross-sectional investigations including participants with different degrees of habituation to CAF may explain the lack of consistency when concluding about tolerance to the ergogenic effect of CAF. Lara's et al. [42] crossover design showed that the ergogenicity of CAF was reduced when the substance was consumed daily for 20 days, yet afterwards the ergogenic properties of CAF were maintained. On the contrary, tolerance to some of the side-effects associated to CAF has been observed in habitual consumers of CAF [43]. However, only two previous studies analyzed the impact of CAF intake in habitual CAF consumers using resistance exercise test protocols [18-20]. These investigations indicate that CAF ergogenicity to power output is mostly reduced in individuals habituated to CAF, while only high doses ( $>9 \mathrm{mg} / \mathrm{kg} / \mathrm{b} . \mathrm{m}$.) may exert some benefit in maximal strength $[19,20]$. However, to date, there is no available data regarding the influence of acute CAF intake on power output and bar velocity during ballistic exercises in athletes habitually consuming CAF.

Given the widespread use of the BPT exercise as a mean of developing power output in the upper limbs $[44,45]$ and the widespread use of CAF in sport, it would be interesting to investigate whether acute CAF intake affects power output and bar velocity in athletes habituated to CAF. For this reason, the aim of the present study was to evaluate the effects of the acute intake of 3 and $6 \mathrm{mg} / \mathrm{kg} / \mathrm{b} . \mathrm{m}$. of CAF on power output and bar velocity during five sets of the BPT in participants habituated to CAF. It was hypothesized that acute CAF intake would increase power output and bar velocity during the BPT training session when compared to a control situation, even in participants habituated to CAF.

\section{Materials and Methods}

A randomized, double-blind, PLAC-controlled crossover design was used for this investigation. Initially, the participants performed a familiarization session with the experimental protocols that included a 1 RM measurement for the bench press exercise. Afterwards, they performed 3 different experimental sessions with a one-week interval between sessions to allow for complete recovery and a wash-out of ingested substances (Figure 1). During the 3 experimental sessions, the study participants either ingested a PLAC, $3 \mathrm{mg} / \mathrm{kg} / \mathrm{b} . \mathrm{m}$. of CAF (CAF-3) or $6 \mathrm{mg} / \mathrm{kg} / \mathrm{b} . \mathrm{m}$. of CAF (CAF-6). One hour after ingestion of CAF or PLAC, they performed 5 sets of 2 repetitions of the BPT exercise at $30 \%$ 1 RM. Both CAF and PLAC were administered orally to allow for peak blood CAF concentration during the training session and at least $2 \mathrm{~h}$ after the last meal to avoid any interference of the diet with the absorption of the experimental substances. CAF supplementation was provided to participants in the form of unidentifiable capsules (Caffeine Kick ${ }^{\circledR}$, Olimp Laboratories, Debica, Poland). The manufacturer of the CAF capsules also provided identical PLAC capsules filled with all-purpose flour. Participants refrained from strenuous physical activity the day before the experimental trials but they maintained their training routines during the duration of the experiment to avoid any performance decrement due to inactivity. Additionally, the participants maintained their dietary habits during the study period, including daily CAF intake. They received a list of products containing CAF which could not be consumed within $12 \mathrm{~h}$ of each experimental trial. Compliance was tested verbally and by using dietary records. Additionally, the participants were required to refrain from alcohol and tobacco, medications or dietary supplements for two weeks prior to the experiment. All subjects registered their calorie intake using the "Myfitness pal" software [46] (Under Armour, Baltimore, MD, USA) every $24 \mathrm{~h}$ before the testing procedure, to ensure that the caloric intake was similar between experimental sessions. 


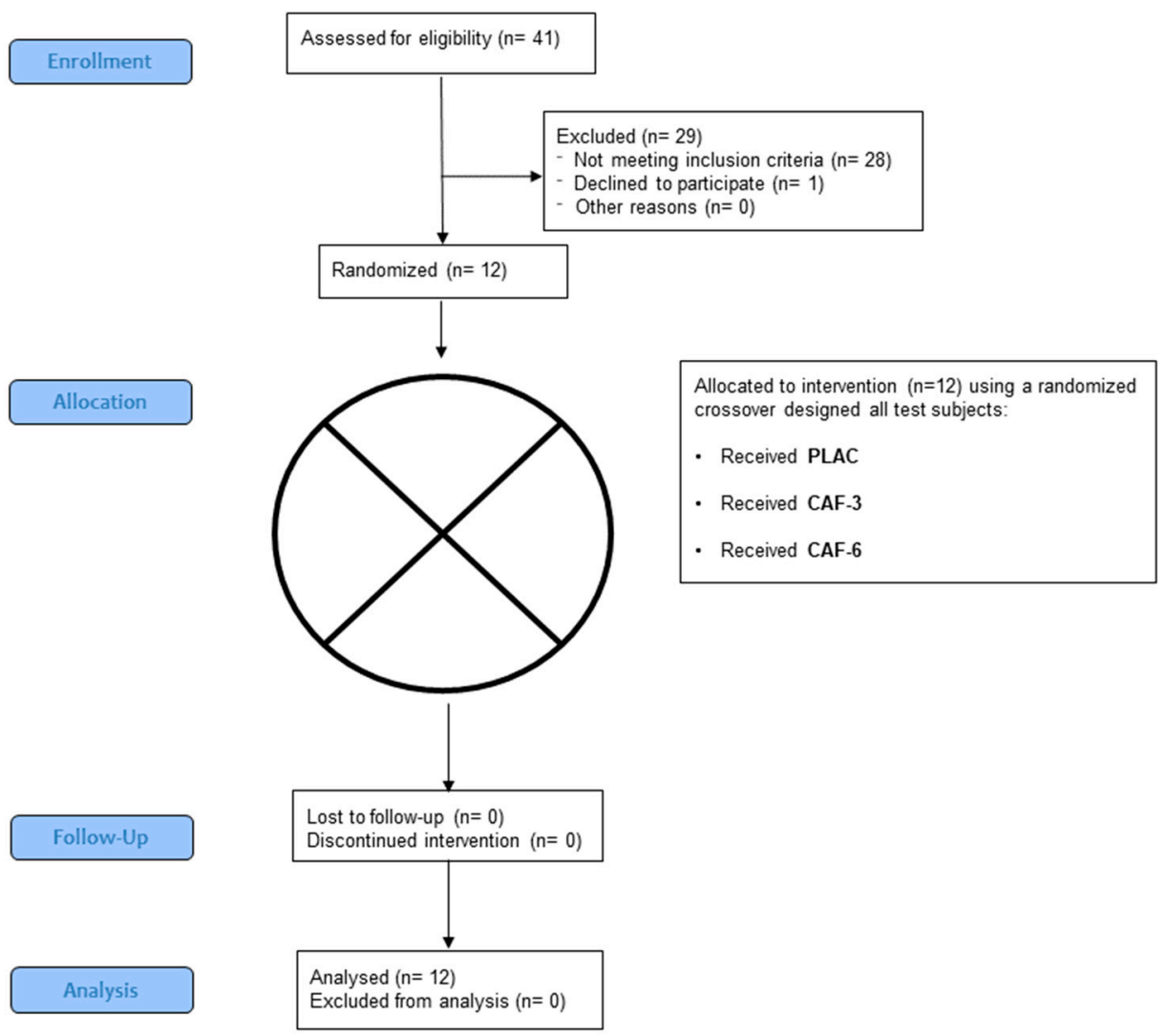

Figure 1. CONSORT flow diagram. $n$-number of participants; PLAC—placebo; CAF-3—caffeine $3 \mathrm{mg} / \mathrm{kg} / \mathrm{b} . \mathrm{m}$; CAF-6 — caffeine $6 \mathrm{mg} / \mathrm{kg} / \mathrm{b} . \mathrm{m}$.

\subsection{Participants}

Twelve healthy strength-trained male athletes (age: $25.3 \pm 1.7$ years., body mass: $88.4 \pm 16.5$ $\mathrm{kg}$, body mass index (BMI): $26.5 \pm 4.7$, bench press $1 \mathrm{RM}: 128.6 \pm 36.0 \mathrm{~kg}$; mean $\pm \mathrm{SD}$ ) volunteered to participate in the study. All participants completed a written consent form after they had been informed of the risks and benefits of the study protocols. The participants had a minimum of 3 years of strength training experience $(4.4 \pm 1.6$ years). All of them were classified as high habitual CAF consumers according to the classification recently proposed by de Souza Gonçalves et al. [40]. They self-reported their daily ingestion of CAF $(5.0 \pm 0.95 \mathrm{mg} / \mathrm{kg} / \mathrm{b} . \mathrm{m} . / \mathrm{day}, 443 \pm 142 \mathrm{mg} /$ day) based on a Food Frequency Questionnaire (FFQ). The inclusion criteria were as follows: (a) free from neuromuscular and musculoskeletal disorders, (b) $1 \mathrm{RM}$ bench press performance with a load of at least $120 \%$ body mass, (c) habitual CAF intake in the range of 4-6 mg/day/kg/b.m. The athletes were excluded from the study when they suffered from any pathology or injury or when they were unable to perform the exercise protocol at the maximum effort. The investigation protocols were approved by the Bioethics Committee for Scientific Research at the Academy of Physical Education in Katowice (March 2019), Poland, according to the ethical standards of the latest version of the Declaration of Helsinki, 2013.

\subsection{Habitual Caffeine Intake Assessment}

Daily CAF intake was measured by an adapted version of the Food Frequency Questionnaire (FFQ) proposed by Bühler et al. [47]. Household measures were employed to individually assess the amount of food consumed during a day, week and month. The list was composed of dietary products with moderate-to-high CAF content including different types of coffee, tea, energy drinks, cocoa products, popular beverages, medications, and CAF supplements. Nutritional tables were used 
for database construction [48-50] and an experienced nutritionist calculated the daily CAF intake for each participant.

\subsection{Familiarization Session and One Repetition Maximum Test}

A familiarization session with the experimental procedures preceded 1 RM testing in the bench press exercise. In this session, the athletes arrived at the laboratory between 9:00 and 10:00 am. and cycled on an ergometer for $5 \mathrm{~min}$. Afterwards, they performed 15 repetitions at $20 \%$ of their estimated $1 \mathrm{RM}$ in the barbell bench press exercise followed by 10 repetitions at $40 \% 1 \mathrm{RM}, 5$ repetitions at $60 \% 1$ $\mathrm{RM}$ and 3 repetitions at $80 \% 1 \mathrm{RM}$. Then they executed single repetitions of the bench press exercise with a 5 min rest interval between successful attempts. The load for each subsequent attempt was increased by 2.5 to $10 \mathrm{~kg}$, and the process was repeated until failure. Hand placement on the barbell was individually selected grip width ( $150 \%$ individual bi-acromial distance). After completing the 1 $\mathrm{RM}$ test in the bench press exercise, the participants performed a maximal BPT on a Smith machine with a load of $30 \% 1 \mathrm{RM}$ from $1 \mathrm{RM}$ bench press test result, with a maximal tempo of movement.

\subsection{Experimental Sessions}

During experimental sessions, the athletes participated in three identical training trials. All trials took place between 9.00 and $11.00 \mathrm{am}$. to avoid the effect of circadian variations on the outcomes of the investigation. After replicating the warm-up procedures of the familiarization trial, the athletes performed 5 sets of the 2 BPT repetitions at 30\% $1 \mathrm{RM}$ on the Smith machine. The repetitions were performed without rest to produce a ballistic movement while the rest interval between sets was 3 min. The participants were encouraged to produce maximal velocity during both the eccentric and concentric phase of the BPT movement. Two spotters were present on each side of the bar during the exercise protocol to ensure safety. To standardize the exercise protocol for all trials, each BPT was performed without bouncing the barbell off the chest, with the lower back in contact with the bench and without any pause between the eccentric and concentric phases of the movement. A rotatory encoder (Tendo Power Analyzer, Tendo Sport Machines, Trencin, Slovakia) was used for instantaneous recording of bar velocity during the whole range of motion, as in previous investigations [51]. During each BPT, peak power output (PP, in $\mathrm{W}$ ) mean power output (MP, in $\mathrm{W})$; peak bar velocity (PV, in $\mathrm{m} / \mathrm{s}$ ); and mean bar velocity (MV, in $\mathrm{m} / \mathrm{s}$ ) were registered. MP and MV were obtained as the mean of the two repetitions while PP and PV were obtained from the best repetition.

\subsection{Statistical Analysis}

Data are presented as the mean $\pm \mathrm{SD}$. All variables presented a normal distribution according to the Shapiro-Wilk test. Verification of differences in peak power output (PP), mean power output (MP), peak bar velocity (PV), and mean bar velocity (MV) was performed using a two-way (substance $x$ set) analysis of variance (ANOVA) with repeated measures. In the event of a significant main effect, post-hoc comparisons were conducted using the Tukey's test. Percent changes and $95 \%$ confidence intervals were also calculated. Effect sizes (Cohen's $d$ ) were reported where appropriate and interpreted as large $(d \geq 0.80)$; moderate ( $d$ between 0.79 and 0.50$)$; small ( $d$ between 0.49 and 0.20$)$; and trivial $(d<0.20) ;[52]$.

\section{Results}

The two-way repeated measures ANOVA indicated no significant substance $\times$ set main interaction effect for MP ( $\mathrm{F}=1.19 ; p=0.32)$; $\mathrm{MV}(\mathrm{F}=1.18 ; p=0.32)$; $\mathrm{PP}(\mathrm{F}=1.05 ; p=0.40)$; $\mathrm{PV}(\mathrm{F}=1.09 ; p=0.38)$. However, there was a significant main effect of substance in $\mathrm{MP}(\mathrm{F}=7.27 ; p<0.01)$ and $\mathrm{MV}(\mathrm{F}=6.75$; $p<0.01)$. No statistically significant main effect of substance was revealed in PP $(\mathrm{F}=2.91 ; p=0.07)$ and PV $(\mathrm{F}=2.63 ; p=0.09$; Table 1$)$. 
Table 1. The main effect for substance on performance variables measured during 5 sets of the bench press throw with the ingestion of 3 and $6 \mathrm{mg} / \mathrm{kg} / \mathrm{b} . \mathrm{m}$. of caffeine or a placebo.

\begin{tabular}{ccccc}
\hline \multirow{2}{*}{$\begin{array}{c}\text { Bench Press Throw } \\
\text { (Mean of the 5 Sets) }\end{array}$} & PLAC & CAF-3 & CAF-6 & \multirow{2}{*}{$\boldsymbol{p}$} \\
\cline { 2 - 4 } & $545 \pm 117$ & $562 \pm 118$ & $560 \pm 107$ & $0.01^{*}$ \\
Mean Power (W) & $1250 \pm 274$ & $1261 \pm 220$ & $1297 \pm 293$ & 0.07 \\
Peak Power (W) & $1.37 \pm 0.05$ & $1.41 \pm 0.05$ & $1.41 \pm 0.06$ & $0.01^{*}$ \\
Mean Velocity (m/s) & $2.14 \pm 0.10$ & $2.16 \pm 0.07$ & $2.17 \pm 0.13$ & 0.09 \\
Peak Velocity (m/s) & &
\end{tabular}

These data represent the mean values of the 5 sets. All data are presented as mean \pm standard deviation. * significant main substance effect. PLAC: placebo; CAF-3: caffeine $3 \mathrm{mg} / \mathrm{kg} / \mathrm{b} . \mathrm{m}$; CAF-6: caffeine $6 \mathrm{mg} / \mathrm{kg} / \mathrm{b} . \mathrm{m}$.

Post hoc analyses for main effect of substance indicated significant increases in MP $(p<0.01$; ES $=0.14)$ and MV ( $p=0.01$; ES $=0.78)$ in BPT (mean of the 5 sets) after the intake of CAF-3 compared to PLAC as well as significant increases in MP $(p=0.01 ; \mathrm{ES}=0.13)$ and MV $(p=0.01 ; \mathrm{ES}=0.72)$ in the BPT (mean of the 5 sets) after the intake of CAF- 6 compared to PLAC. There were no significant differences in MP and MV between the two doses of CAF (CAF-3 vs. CAF-6). The results of particular sets in MP, MV, PP, and PV as well ES between PLAC and CAF-3, CAF-6 in each set are presented in Table 2.

Table 2. Power output and bar velocity during 5 sets of the bench press throw with the ingestion of 3 and $6 \mathrm{mg} / \mathrm{kg} / \mathrm{b} . \mathrm{m}$. of caffeine or with a placebo.

\begin{tabular}{|c|c|c|c|c|c|c|}
\hline & Conditions & Set 1 & Set 2 & Set 3 & Set 4 & Set 5 \\
\hline \multicolumn{7}{|c|}{ Mean Power (W) } \\
\hline & PLAC & $542 \pm 126$ & $548 \pm 119$ & $551 \pm 117$ & $543 \pm 115$ & $540 \pm 114$ \\
\hline & $(95 \% \mathrm{CI})$ & (462 to 622 ) & (472 to 623$)$ & (477 to 626$)$ & $(470$ to 616$)$ & (468 to 613 ) \\
\hline & CAF-3 & $552 \pm 124$ & $564 \pm 115$ & $567 \pm 116$ & $557 \pm 112$ & $570 \pm 124$ \\
\hline & $(95 \% \mathrm{CI})$ & (473 to 631$)$ & (490 to 637 ) & (493 to 640 ) & (486 to 628$)$ & (492 to 649 ) \\
\hline & CAF-6 & $559 \pm 109$ & $563 \pm 107$ & $562 \pm 113$ & $556 \pm 103$ & $562 \pm 105$ \\
\hline & $(95 \% \mathrm{CI})$ & (489 to 628 ) & (495 to 631$)$ & (489 to 634$)$ & (491 to 621$)$ & (496 to 629$)$ \\
\hline \multirow{2}{*}{ ES } & PLAC vs. CAF-3 & 0.07 & 0.14 & 0.14 & 0.12 & 0.25 \\
\hline & PLAC vs. CAF-6 & 0.14 & 0.13 & 0.09 & 0.12 & 0.20 \\
\hline \multicolumn{7}{|c|}{ Peak Power (W) } \\
\hline \multirow{8}{*}{ ES } & PLAC & $1245 \pm 248$ & $1252 \pm 291$ & $1286 \pm 378$ & $1244 \pm 252$ & $1222 \pm 250$ \\
\hline & $(95 \% \mathrm{CI})$ & (1088 to 1402$)$ & (1067 to 1437$)$ & (1045 to 1526$)$ & (1083 to 1404$)$ & (1063 to 1381 ) \\
\hline & CAF-3 & $1243 \pm 218$ & $1252 \pm 265$ & $1285 \pm 216$ & $1241 \pm 199$ & $1283 \pm 224$ \\
\hline & $(95 \% \mathrm{CI})$ & (1105 to 1382 ) & (1084 to 1420$)$ & (1147 to 1422 ) & (1114 to 1368$)$ & (1141 to 1425$)$ \\
\hline & CAF-6 & $1253 \pm 294$ & $1338 \pm 362$ & $1338 \pm 344$ & $1278 \pm 255$ & $1278 \pm 250$ \\
\hline & $(95 \% \mathrm{CI})$ & (1066 to 1440$)$ & (1107 to 1568$)$ & (1119 to 1556$)$ & (1116 to 1440$)$ & (1119 to 1437 ) \\
\hline & PLAC vs. CAF-3 & 0.01 & 0.00 & 0.01 & 0.01 & 0.26 \\
\hline & PLAC vs. CAF-6 & 0.03 & 0.26 & 0.14 & 0.13 & 0.22 \\
\hline \multicolumn{7}{|c|}{ Mean Velocity (m/s) } \\
\hline & PLAC & $1.36 \pm 0.06$ & $1.38 \pm 0.08$ & $1.38 \pm 0.05$ & $1.37 \pm 0.04$ & $1.36 \pm 0.07$ \\
\hline & $(95 \% \mathrm{CI})$ & (1.32 to 1.40$)$ & (1.33 to 1.43$)$ & (1.35 to 1.41$)$ & (1.35 to 1.41$)$ & (1.32 to 1.40$)$ \\
\hline & CAF-3 & $1.39 \pm 0.07$ & $1.42 \pm 0.05$ & $1.43 \pm 0.05$ & $1.40 \pm 0.05$ & $1.43 \pm 0.05$ \\
\hline & $(95 \% \mathrm{CI})$ & (1.34 to 1.43$)$ & (1.39 to 1.45$)$ & (1.40 to 1.46$)$ & (1.37 to 1.43$)$ & (1.40 to 1.46$)$ \\
\hline & CAF-6 & $1.41 \pm 0.07$ & $1.42 \pm 0.07$ & $1.41 \pm 0.05$ & $1.40 \pm 0.07$ & $1.42 \pm 0.09$ \\
\hline & $(95 \% \mathrm{CI})$ & (1.36 to 1.45$)$ & (1.37 to 1.47$)$ & (1.38 to 1.45$)$ & (1.35 to 1.44$)$ & (1.37 to 1.47$)$ \\
\hline \multirow{2}{*}{ ES } & PLAC vs. CAF-3 & 0.46 & 0.60 & 1.0 & 0.40 & 1.15 \\
\hline & PLAC vs. CAF-6 & 0.77 & 0.60 & 0.6 & 0.33 & 0.77 \\
\hline \multicolumn{7}{|c|}{ Peak Velocity (m/s) } \\
\hline & PLAC & $2.13 \pm 0.08$ & $2.15 \pm 0.11$ & $2.17 \pm 0.13$ & $2.15 \pm 0.12$ & $2.10 \pm 0.14$ \\
\hline & $(95 \% \mathrm{CI})$ & (2.08 to 2.18 ) & (2.08 to 2.22 ) & (2.09 to 2.26 ) & (2.07 to 2.22$)$ & (2.01 to 2.19 ) \\
\hline & CAF-3 & $2.14 \pm 0.08$ & $2.17 \pm 0.07$ & $2.18 \pm 0.09$ & $2.14 \pm 0.05$ & $2.19 \pm 0.08$ \\
\hline & $(95 \% \mathrm{CI})$ & (2.09 to 2.18$)$ & (2.12 to 2.22 ) & (2.12 to 2.24$)$ & (2.11 to 2.17 ) & (2.14 to 2.25$)$ \\
\hline & CAF-6 & $2.16 \pm 0.12$ & $2.18 \pm 0.13$ & $2.19 \pm 0.14$ & $2.17 \pm 0.14$ & $2.17 \pm 0.17$ \\
\hline & $(95 \% \mathrm{CI})$ & (2.08 to 2.23 ) & (2.10 to 2.26 ) & (2.10 to 2.28 ) & (2.09 to 2.26 ) & (2.06 to 2.28$)$ \\
\hline \multirow{2}{*}{ ES } & PLAC vs. CAF-3 & 0.13 & 0.22 & 0.09 & 0.11 & 0.79 \\
\hline & PLAC vs. CAF-6 & 0.29 & 0.25 & 0.15 & 0.15 & 0.45 \\
\hline
\end{tabular}

All data are presented as mean \pm standard deviation. CI: confidence interval. ES: effect size. 
Figures 2 and 3 represent the individual responses induced by CAF-3 and CAF-6, in comparison to the placebo, for MP and MV. The 11 out of 12 participants showed an increase in MP and MV after the ingestion of CAF-3, while CAF-6 produced higher values for MP and MV in 10 out of 12 participants.



Figure 2. Individual differences in mean power output during 5 sets of bench press throw (BPT) between caffeine and placebo conditions.

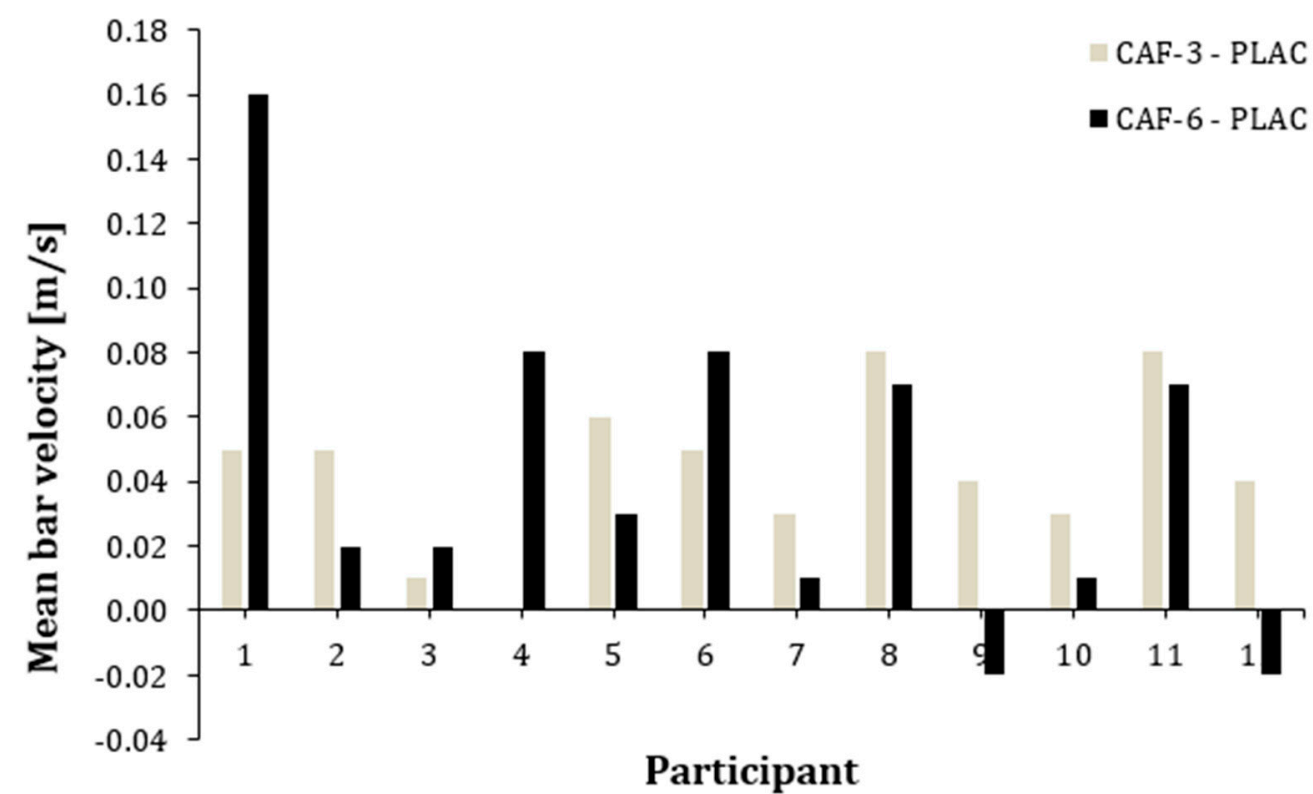

Figure 3. Individual differences in mean bar velocity during 5 sets of bench press throw (BPT) between caffeine and placebo conditions.

The y-axis represents the difference in mean bar velocity output during the 5 sets of BPT between PLAC-CAF-3; PLAC-CAF-6 for each individual.

\section{Discussion}

The main finding of this study was that acute CAF intake has a positive effect on MP and MV during a training session of the BPT performed at 30\% 1 RM. Interestingly, both 3 and $6 \mathrm{mg} / \mathrm{kg} / \mathrm{b} . \mathrm{m}$. doses of 
CAF had similar effectiveness in enhancing performance when compared to PLAC. Additionally, the ergogenic effect of CAF on MP and MV was evident in most of participants, as all of them responded by improving performance with either CAF- 3 or CAF-6, even when they were catalogued as individuals habituated to CAF (Figures 2 and 3). However, the study did not show significant changes in PP and $\mathrm{PV}$ after CAF intake with either dose of CAF ( 3 and $6 \mathrm{mg} / \mathrm{kg} / \mathrm{b} . \mathrm{m}$.) compared to PLAC. These outcomes suggest that acute CAF intake in a moderate dose (from 3 to $6 \mathrm{mg} / \mathrm{kg} / \mathrm{b} . \mathrm{m}$.) is effective in increasing mean power and bar velocity during the BPT without a significant influence on peak values of these variables. These results suggest that CAF can be effectively used to acutely improve this power-specific training routine even with individuals habituated to $\mathrm{CAF}$, although the long-term training effects with CAF should be further investigated.

The y-axis represents the difference in mean power output during the 5 sets of BPT between PLAC-CAF-3; PLAC-CAF-6 for each individual.

Previous research showed that acute $\mathrm{CAF}$ intake increases power output during the bench press exercise [8,14-16]. However, most of these studies included only one set of the exercise which is not the habitual practice during sports training, where several sets of a particular exercise are performed in order to obtain significant adaptations derived from training. In presented study, the main effect of increase in MP and MV after the intake of CAF-3 and CAF- 6 over the placebo has occurred for training session consisting several sets (Table 2). The ergogenic effect of CAF observed during the BPT is partly consistent with the results of previous findings [8,16]. However, it should be emphasized that this is the first study investigating the effects of CAF during a training session that includes several sets of a ballistic exercise. Experimental procedures with the use of CAF in which more than one set of an upper body exercise are used are scarce [18,53,54]. The study of Lane and Byrd [53] showed that the intake of $300 \mathrm{mg}$ of CAF, representing $3.5 \mathrm{mg} / \mathrm{kg} / \mathrm{b} . \mathrm{m}$. increased peak velocity during 10 sets of the bench press exercise at $80 \% 1$ RM compared to PLAC. Wilk et al. [18] did not show significant changes after the intake of different doses of CAF $(3,6$, and $9 \mathrm{mg} / \mathrm{kg} / \mathrm{b} . \mathrm{m}$.) in both, mean and peak power output and bar velocity during the BP exercise at 50\% 1 RM ( 3 sets of 5 repetitions), although this investigation was carried out in athletes habituated to CAF. No changes in mean and peak bar velocity after CAF intake of $150 \mathrm{mg}$, representing $1.74 \mathrm{mg} / \mathrm{kg} / \mathrm{b} . \mathrm{m}$. were observed in a study by Lane et al. [54] where 10 sets of 3 repetitions of the bench press exercise were performed at $80 \% 1 \mathrm{RM}$. The current study is quite innovative because it is the first investigation geared to assess the effects of CAF intake on power output by using a ballistic upper body exercise with a low external load (30\% $1 \mathrm{RM})$, geared for power training of athletes [55]. The current state of the literature, indicates that CAF is useful in increasing power during one or multiple sets of the bench press exercise when the dose ingested is $>3 \mathrm{mg} / \mathrm{kg} / \mathrm{b} . \mathrm{m}$., but it seems particularly effective when using low and moderate loads during an explosive exercise, such as the BPT.

The overall increase of MP and MV during the training session of the BPT after ingestion of CAF-3 and CAF- 6 can be also attributed to increased pre-exercise central excitability. Specifically, the pre-exercise ingestion of CAF would allow the athletes to maintain a certain amount of force even in the presence of biochemical changes within the working muscle that lead to fatigue [3]. Under this theory, CAF intake would allow a higher physical performance because it would help to maintain the neural response even in the presence of metabolic perturbations such as low muscle $\mathrm{pH}$. This effect may be accompanied by reductions in interstitial potassium accumulation found after CAF intake [2], that ultimately leads to the maintenance of excitability during exercise [33,56]. In the central nervous system (CNS), CAF binds to adenosine receptors that influence the release of neurotransmitters, such as noradrenaline and acetylcholine [4,57-59] and consequently, increase muscle tension [60]. However, in the current investigation, this purported effect of CAF on CNS was not sufficient to enhance PP and PV during the BPT at 30\% 1 RM. Thus, reduced fatigue through CAF-induced modulation of both peripheral and central neural processes may explain the obtained results and higher MP and MV of the bar during the BPT training session. Nevertheless, the association of the ergogenic effect with the 
mechanisms that allowed this ergogenic effect is speculative at this moment because no measurements were carried out to test the origin of caffeine's ergogenic effects.

It should be taken into consideration that the study participants in the current study were habitual CAF users. In contrast, most of the investigations aimed at determination of the ergogenic effect of CAF on muscle performance have selected individuals unhabituated to this stimulant or with low-to-moderate daily consumption of CAF (e.g., from 58 to $250 \mathrm{mg} /$ day), [11,16,34], to avoid the effects that tolerance to CAF may. However, CAF is an ergogenic aid frequently used in training and competition and it is likely that some athletes seeking for ergogenic benefits of CAF are already habituated to this substance due to the chronic use of caffeine-containing supplements during training and competition. In fact, previous investigations have suggested that between $75 \%$ and $90 \%$ of athletes use CAF in competitive and training settings [35,36,61], suggesting that studies on the effect of acute CAF intake on physical performance during real training and competition settings are particularly important in athletes habituated to CAF. In this respect, previous research using well-controlled CAF treatments has suggested that the habitual intake of this stimulant may progressively reduce its ergogenic effect on exercise performance [42,62] and then, it has been speculated that the ergogenic effect of CAF could be dampened in habitual CAF users.

To the authors' knowledge, only three previous studies analyzed power output of the upper limbs in a group of participants habituated to CAF [9,18-20]. The study of Sabol et al. [9] showed an increase in medicine ball throwing distance after the acute intake of $6 \mathrm{mg} / \mathrm{kg} / \mathrm{b} . \mathrm{m}$. of CAF but the doses of 2 and $4 \mathrm{mg} / \mathrm{kg} / \mathrm{b} . \mathrm{m}$. did not show any differences with the PLAC. The study by Wilk et al. [18] did not show increases in power output and bar velocity during the bench press exercise in high habitual CAF users that ingested from 3 to $9 \mathrm{mg} / \mathrm{kg} / \mathrm{b} . \mathrm{m}$. Although it has been theorized that the reduction in the ergogenic effects of CAF in habitual users can be modified using doses greater than the daily habitual intake [63], previous investigations indicate that athletes habituated to CAF do not benefit from the acute ingestion of CAF in doses above their habitual intake while the prevalence of side effects is greatly increased $[19,20]$. Interestingly, participants in the presented study self-reported their daily ingestion of CAF, which amounted to $5.0 \pm 0.95 \mathrm{mg} / \mathrm{kg} / \mathrm{b} . \mathrm{m} .,(443 \pm 142 \mathrm{mg}$ of CAF per day), and the acute CAF doses (especially CAF-3) and some performance enhancements were obtained even when de dose of CAF did not exceed the value of habitual consumption. In any case, although the current investigation found a positive effect of CAF on mean power output and mean bar velocity during the BPT in athletes habituated to CAF, it is still possible that the effect of this substance is higher in unhabituated individuals.

In addition to its strengths, the current study presents limitations that should be addressed. Although the results showed a significant main effect on MP and MV after CAF intake, the direct causes of these changes cannot be determined and explained. The study did not include biochemical analysis which could explain the obtained results. In addition, blood samples were not obtained and thus, we have no data about serum CAF concentrations with each of the dosages of CAF employed in this investigation. Further, we did not analyze the genetic intolerance on CAF in the tested subjects. However, the participants of this study did not report any side effects after consuming CAF in the six months prior to the experiment. Due to the fact that the response to CAF is related to the individual tolerance of this substance [42], the dose [19,20], and gender [64] therefore the results of this study should only be translated to males habituated to CAF who use low to moderate CAF doses to enhance performance. Another limitation of the study was that the $1 \mathrm{RM}$ test was performed using the barbell bench press exercise while the BPT was performed on a Smith machine during the experimental trials to increase the security of participants and investigators. Although there is a high transfer between the results obtained in both types of exercise, the calculation of loading would be more reliable if both evaluations were performed on the same resistance exercise. In any case, this limitation did not affect the outcomes of the investigation because the load was the same for all experimental trials. 


\section{Conclusions}

The results of the present study indicate that acute doses of CAF, between 3 and $6 \mathrm{mg} / \mathrm{kg} / \mathrm{b} . \mathrm{m}$., ingested before the onset of an explosive resistance exercise produced an overall effect on mean power output and mean bar velocity during a BPT training session in a group of habitual CAF users. The main effect in mean power and bar velocity was found in several sets during the trial which may indicate that the use of CAF was effective in increasing performance in the whole training session. In contrast, no significant changes were observed for peak power output and peak bar velocity. These results suggest that the ingestion of CAF prior to ballistic exercise can enhance the outcomes of resistance training. However, the results of our study refer only to power output and bar velocity of the upper limbs during the BPT with an external load of 30\% $1 \mathrm{RM}$ and further investigations should consider the effect of CAF with different loads or the use of lower-body exercises.

Author Contributions: Data curation, M.W., A.F., M.K., and M.G.; formal analysis, M.W., A.F.; investigation, M.W., A.F., M.K., and M.G.; methodology, M.W. and A.F.; project administration, A.F., M.K., and M.G.; software, A.F., M.K., and M.G.; supervision, M.W., A.Z., and J.D.C.; writing-original draft, M.W., A.F., M.K., and J.D.C.; writing-review and editing, M.W., A.Z., and J.D.C. All authors have read and agreed to the published version of the manuscript.

Funding: This study would not have been possible without our participants' commitment, time and effort. The study was supported and funded by the statutory research of the Jerzy Kukuczka Academy of Physical Education in Katowice, Poland.

Conflicts of Interest: The authors declare that they have no conflicts of interest.

\section{References}

1. Maughan, R.J.; Burke, L.M.; Dvorak, J.; Larson-Meyer, D.E.; Peeling, P.; Phillips, S.M.; Rawson, E.S.; Walsh, N.P.; Garthe, I.; Geyer, H.; et al. IOC Consensus Statement: Dietary Supplements and the High-Performance Athlete. Int. J. Sport Nutr. Exerc. Metab. 2018, 28, 104-125. [CrossRef] [PubMed]

2. Shushakov, V.; Stubbe, C.; Peuckert, A.; Endeward, V.; Maassen, N. The relationships between plasma potassium, muscle excitability and fatigue during voluntary exercise in humans: Plasma potassium, muscle excitability and fatigue in humans. Exp. Physiol. 2007, 92, 705-715. [CrossRef] [PubMed]

3. Bowtell, J.L.; Mohr, M.; Fulford, J.; Jackman, S.R.; Ermidis, G.; Krustrup, P.; Mileva, K.N. Improved Exercise Tolerance with Caffeine Is Associated with Modulation of both Peripheral and Central Neural Processes in Human Participants. Front. Nutr. 2018, 5, 6. [CrossRef] [PubMed]

4. Davis, J.M.; Zhao, Z.; Stock, H.S.; Mehl, K.A.; Buggy, J.; Hand, G.A. Central nervous system effects of caffeine and adenosine on fatigue. Am. J. Physiol. Regul. Integr. Comp. Physiol. 2003, 284, R399-R404. [CrossRef]

5. Elmenhorst, D.; Meyer, P.T.; Matusch, A.; Winz, O.H.; Bauer, A. Caffeine occupancy of human cerebral A1 adenosine receptors: In vivo quantification with 18F-CPFPX and PET. J. Nucl. Med. 2012, 53, 1723-1729. [CrossRef]

6. Grgic, J.; Grgic, I.; Pickering, C.; Schoenfeld, B.J.; Bishop, D.J.; Pedisic, Z. Wake up and smell the coffee: Caffeine supplementation and exercise performance-An umbrella review of 21 published meta-analyses. Br. J. Sports Med.. in press. [CrossRef]

7. Grgic, J.; Trexler, E.T.; Lazinica, B.; Pedisic, Z. Effects of caffeine intake on muscle strength and power: A systematic review and meta-analysis. J. Int. Soc. Sports Nutr. 2018, 15, 11. [CrossRef]

8. Pallarés, J.G.; Fernández-Elías, V.E.; Ortega, J.F.; Muñoz, G.; Muñoz-Guerra, J.; Mora-Rodríguez, R. Neuromuscular Responses to Incremental Caffeine Doses: Performance and Side Effects. Med. Sci. Sport Exer. 2013, 45, 2184-2192. [CrossRef]

9. Sabol, F.; Grgic, J.; Mikulic, P. The Effects of 3 Different Doses of Caffeine on Jumping and Throwing Performance: A Randomized, Double-Blind, Crossover Study. Int. J. Sports Physiol. Perform. 2019, 14, 1170-1177. [CrossRef]

10. Tallis, J.; Yavuz, H.C.M. The effects of low and moderate doses of caffeine supplementation on upper and lower body maximal voluntary concentric and eccentric muscle force. Appl. Physiol. Nutr. Metab. 2018, 43, 274-281. [CrossRef] 
11. Astorino, T.A.; Rohmann, R.L.; Firth, K. Effect of caffeine ingestion on one-repetition maximum muscular strength. Eur. J. Appl. Physiol. 2007, 102, 127-132. [CrossRef] [PubMed]

12. Forbes, S.C.; Candow, D.G.; Little, J.P.; Magnus, C.; Chilibeck, P.D. Effect of Red Bull energy drink on repeated Wingate cycle performance and bench-press muscle endurance. Int. J. Sport Nutr. Exerc. Metab. 2007, 17, 433-444. [CrossRef] [PubMed]

13. Williams, A.D.; Cribb, P.J.; Cooke, M.B.; Hayes, A. The effect of ephedra and caffeine on maximal strength and power in resistance-trained athletes. J. Strength Cond. Res. 2008, 22, 464-470. [CrossRef] [PubMed]

14. Venier, S.; Grgic, J.; Mikulic, P. Caffeinated Gel Ingestion Enhances Jump Performance, Muscle Strength, and Power in Trained Men. Nutrients 2019, 11, 937. [CrossRef] [PubMed]

15. Astley, C.; Souza, D.B.; Polito, M.D. Acute Specific Effects of Caffeine-containing Energy Drink on Different Physical Performances in Resistance-trained Men. Int. J. Exerc. Sci. 2018, 11, 260-268. [PubMed]

16. Grgic, J.; Mikulic, P. Caffeine ingestion acutely enhances muscular strength and power but not muscular endurance in resistance-trained men. Eur. J. Sport Sci. 2017, 17, 1029-1036. [CrossRef] [PubMed]

17. Del Coso, J.; Salinero, J.J.; González-Millán, C.; Abián-Vicén, J.; Pérez-González, B. Dose response effects of a caffeine-containing energy drink on muscle performance: A repeated measures design. J. Int. Soc. Sports Nutr. 2012, 9, 21. [CrossRef]

18. Wilk, M.; Filip, A.; Krzysztofik, M.; Maszczyk, A.; Zajac, A. The Acute Effect of Various Doses of Caffeine on Power Output and Velocity during the Bench Press Exercise among Athletes Habitually Using Caffeine. Nutrients 2019, 11, 1465. [CrossRef]

19. Wilk, M.; Krzysztofik, M.; Filip, A.; Zajac, A.; Del Coso, J. The Effects of High Doses of Caffeine on Maximal Strength and Muscular Endurance in Athletes Habituated to Caffeine. Nutrients 2019, 11, 1912. [CrossRef]

20. Wilk, M.; Krzysztofik, M.; Filip, A.; Zajac, A.; Del Coso, J. Correction: Wilk et al. "The Effects of High Doses of Caffeine on Maximal Strength and Muscular Endurance in Athletes Habituated to Caffeine." Nutrients 2019, 11, 1912. Nutrients 2019, 11, 2660. [CrossRef]

21. Stastny, P.; Golas, A.; Blazek, D.; Maszczyk, A.; Wilk, M.; Pietraszewski, P.; Petr, M.; Uhlir, P.; Zajac, A. A systematic review of surface electromyography analyses of the bench press movement task. PLoS ONE 2017, 12, e0171632. [CrossRef]

22. Wilk, M.; Golas, A.; Stastny, P.; Nawrocka, M.; Krzysztofik, M.; Zajac, A. Does Tempo of Resistance Exercise Impact Training Volume? J. Hum. Kinet. 2018, 62, 241-250. [CrossRef]

23. Cormie, P.; McGuigan, M.R.; Newton, R.U. Developing Maximal Neuromuscular Power: Part 1-Biological Basis of Maximal Power Production. Sports Med. 2011, 41, 17-38. [CrossRef]

24. Newton, R.U.; Kraemer, W.J.; Häkkinen, K.; Humphries, B.J.; Murphy, A.J. Kinematics, Kinetics, and Muscle Activation during Explosive Upper Body Movements. J. Appl. Biomech. 1996, 12, 31-43. [CrossRef]

25. Samozino, P.; Rejc, E.; Di Prampero, P.E.; Belli, A.; Morin, J.-B. Optimal Force-Velocity Profile in Ballistic Movements-Altius. Med. Sci. Sport Exer. 2012, 44, 313-322. [CrossRef]

26. Baker, D. Comparison of upper-body strength and power between professional and college-aged rugby league players. J. Strength Cond. Res. 2001, 15, 30-35.

27. Cronin, J.B.; Owen, G.J. Upper-Body Strength and Power Assessment in Women Using a Chest Pass. J. Strength Cond. Res. 2004, 18, 401.

28. Liossis, L.D.; Forsyth, J.; Liossis, C.; Tsolakis, C. The Acute Effect of Upper-Body Complex Training on Power Output of Martial Art Athletes as Measured by the Bench Press Throw Exercise. J. Hum. Kinet. 2013, 39, 167-175. [CrossRef]

29. Terzis, G.; Georgiadis, G.; Vassiliadou, E.; Manta, P. Relationship between shot put performance and triceps brachii fiber type composition and power production. Eur. J. Appl. Physiol. 2003, 90, 10-15. [CrossRef]

30. Sarabia, J.M.; Moya-Ramón, M.; Hernández-Davó, J.L.; Fernandez-Fernandez, J.; Sabido, R. The effects of training with loads that maximise power output and individualised repetitions vs. traditional power training. PLoS ONE 2017, 12, e0186601. [CrossRef]

31. Burke, L.M. Practical Issues in Evidence-Based Use of Performance Supplements: Supplement Interactions, Repeated Use and Individual Responses. Sports Med. 2017, 47, 79-100. [CrossRef]

32. Wilk, M.; Krzysztofik, M.; Maszczyk, A.; Chycki, J.; Zajac, A. The acute effects of caffeine intake on time under tension and power generated during the bench press movement. J. Int. Soc. Sports Nutr. 2019, 16, 8. [CrossRef] 
33. Mohr, M.; Nielsen, J.J.; Bangsbo, J. Caffeine intake improves intense intermittent exercise performance and reduces muscle interstitial potassium accumulation. J. Appl. Physiol. 2011, 111, 1372-1379. [CrossRef]

34. Duncan, M.J.; Oxford, S.W. The Effect of Caffeine Ingestion on Mood State and Bench Press Performance to Failure. J. Strength Cond. Res. 2011, 25, 178-185. [CrossRef]

35. Del Coso, J.; Muñoz, G.; Muñoz-Guerra, J. Prevalence of caffeine use in elite athletes following its removal from the World Anti-Doping Agency list of banned substances. Appl. Physiol. Nutr. Metab. 2011, 36, 555-561. [CrossRef]

36. Aguilar-Navarro, M.; Muñoz, G.; Salinero, J.; Muñoz-Guerra, J.; Fernández-Álvarez, M.; Plata, M.; Del Coso, J. Urine Caffeine Concentration in Doping Control Samples from 2004 to 2015. Nutrients 2019, 11, 286. [CrossRef]

37. Svenningsson, P.; Nomikos, G.G.; Fredholm, B.B. The stimulatory action and the development of tolerance to caffeine is associated with alterations in gene expression in specific brain regions. J. Neurosci. 1999, 19, 4011-4022. [CrossRef]

38. Fredholm, B.B.; Baättig, K.; Holmén, J.; Nehlig, A.; Zvartau, E.E. Actions of caffeine in the brain with special reference to factors that contribute to its widespread use. Pharmacol. Rev. 1999, 51, 83-133.

39. Dodd, S.L.; Brooks, E.; Powers, S.K.; Tulley, R. The effects of caffeine on graded exercise performance in caffeine naive versus habituated subjects. Eur. J. Appl. Physiol. Occup. Physiol. 1991, 62, 424-429. [CrossRef]

40. de Souza Gonçalves, L.; de Salles Painelli, V.; Yamaguchi, G.; de Oliveira, L.F.; Saunders, B.; da Silva, R.P.; Maciel, E.; Artioli, G.G.; Roschel, H.; Gualano, B. Dispelling the myth that habitual caffeine consumption influences the performance response to acute caffeine supplementation. J. Appl. Physiol. 2017, 123, 213-220. [CrossRef]

41. Bell, D.G.; McLellan, T.M. Exercise endurance 1, 3, and $6 \mathrm{~h}$ after caffeine ingestion in caffeine users and nonusers. J. Appl. Physiol. 2002, 93, 1227-1234. [CrossRef] [PubMed]

42. Lara, B.; Ruiz-Moreno, C.; Salinero, J.J.; Del Coso, J. Time course of tolerance to the performance benefits of caffeine. PLoS ONE 2019, 14, e0210275. [CrossRef] [PubMed]

43. Ruiz-Moreno, C.; Lara, B.; Salinero, J.J.; Brito de Souza, D.; Ordovás, J.M.; Del Coso, J. Time course of tolerance to adverse effects associated with the ingestion of a moderate dose of caffeine. Eur. J. Nutr. 2020, 2010, 1-10. [CrossRef]

44. García-Ramos, A.; Padial, P.; García-Ramos, M.; Conde-Pipó, J.; Argüelles-Cienfuegos, J.; Štirn, I.; Feriche, B. Reliability Analysis of Traditional and Ballistic Bench Press Exercises at Different Loads. J. Hum. Kinet. 2015, 47, 51-59. [CrossRef]

45. Marques, M.C.; van den Tillaar, R.; Vescovi, J.D.; González-Badillo, J.J. Relationship Between Throwing Velocity, Muscle Power, and Bar Velocity During Bench Press in Elite Handball Players. Int. J. Sports Physiol. Perform. 2007, 2, 414-422. [CrossRef]

46. Teixeira, V.; Voci, S.M.; Mendes-Netto, R.S.; da Silva, D.G. The relative validity of a food record using the smartphone application MyFitnessPal: Relative validity of a smartphone dietary record. Nutr. Diet. 2018, 75, 219-225. [CrossRef]

47. Bühler, E.; Lachenmeier, D.W.; Winkler, G. Development of a tool to assess caffeine intake among teenagers and young adults. Ernahrungs. Umschau. 2014, 61, 58-63.

48. Frankowski, M.; Kowalski, A.; Ociepa, A.; Siepak, J.; Niedzielski, P. Caffeine levels in various caffeine-rich and decaffeinated coffee grades and coffee extracts marketed in Poland. Bromat. Chem. Toksykol. 2008, 1, 21-27.

49. Burke, L.M. Caffeine and sports performance. Appl. Physiol. Nutr. Metab. 2008, 33, 1319-1334. [CrossRef]

50. SELF Nutrition Data. Available online: https://nutritiondata.self.com/ (accessed on 2 April 2019).

51. García-Ramos, A.; Pestaña-Melero, F.L.; Pérez-Castilla, A.; Rojas, F.J.; Haff, G.G. Differences in the Load-Velocity Profile Between 4 Bench-Press Variants. Int. J. Sports Physiol. Perform. 2018, 13, 326-331. [CrossRef]

52. Cohen, J. Statistical Power Analysis for the Behavioral Sciences, 2nd ed.; Routledge: New York, NY, USA, 2013.

53. Lane, M.; Byrd, M. Effects of Pre-Workout Supplements on Power Maintenance in Lower Body and Upper Body Tasks. JFMK 2018, 3, 11. [CrossRef]

54. Lane, M.T.; Byrd, M.T.; Bell, Z.; Hurley, T. Effects of Supplementation of a Pre-workout on Power Maintenance in Lower Body and Upper Body Tasks in Women. JFMK 2019, 4, 18. [CrossRef] 
55. Cormie, P.; McGuigan, M.R.; Newton, R.U. Developing maximal neuromuscular power: Part 2-training considerations for improving maximal power production. Sports Med. 2011, 41, 125-146. [CrossRef]

56. Fortune, E.; Lowery, M.M. Effect of Extracellular Potassium Accumulation on Muscle Fiber Conduction Velocity: A Simulation Study. Ann. Biomed. Eng. 2009, 37, 2105-2117. [CrossRef]

57. Daly, J.W.; Shi, D.; Nikodijevic, O.; Jacobson, K.A. The role of adenosine receptors in the central action of caffeine. Pharmacopsychoecologia 1994, 7, 201-213.

58. Goldstein, E.R.; Ziegenfuss, T.; Kalman, D.; Kreider, R.; Campbell, B.; Wilborn, C.; Taylor, L.; Willoughby, D.; Stout, J.; Graves, B.S.; et al. International society of sports nutrition position stand: Caffeine and performance. J. Int. Soc. Sports Nutr. 2010, 7, 5. [CrossRef]

59. Ferré, S. Mechanisms of the psychostimulant effects of caffeine: Implications for substance use disorders. Psychopharmacology 2016, 233, 1963-1979. [CrossRef]

60. Behrens, M.; Mau-Moeller, A.; Weippert, M.; Fuhrmann, J.; Wegner, K.; Skripitz, R.; Bader, R.; Bruhn, S. Caffeine-induced increase in voluntary activation and strength of the quadriceps muscle during isometric, concentric and eccentric contractions. Sci. Rep. 2015, 5, 10209. [CrossRef]

61. Desbrow, B.; Leveritt, M. Awareness and Use of Caffeine by Athletes Competing at the 2005 Ironman Triathlon World Championships. Int. J. Sport Nutr. Exerc. Metab. 2006, 16, 545-558. [CrossRef]

62. Beaumont, R.; Cordery, P.; Funnell, M.; Mears, S.; James, L.; Watson, P. Chronic ingestion of a low dose of caffeine induces tolerance to the performance benefits of caffeine. J. Sports Sci. 2017, 35, 1920-1927. [CrossRef]

63. Pickering, C.; Kiely, J. Are the Current Guidelines on Caffeine Use in Sport Optimal for Everyone? Inter-individual Variation in Caffeine Ergogenicity, and a Move Towards Personalised Sports Nutrition. Sports Med. 2018, 48, 7-16. [CrossRef] [PubMed]

64. Mielgo-Ayuso, J.; Marques-Jiménez, D.; Refoyo, I.; Del Coso, J.; León-Guereño, P.; Calleja-González, J. Effect of Caffeine Supplementation on Sports Performance Based on Differences Between Sexes: A Systematic Review. Nutrients 2019, 11, 2313. [CrossRef] [PubMed]

(C) 2020 by the authors. Licensee MDPI, Basel, Switzerland. This article is an open access article distributed under the terms and conditions of the Creative Commons Attribution (CC BY) license (http://creativecommons.org/licenses/by/4.0/). 